\title{
Serum factor affecting neutrophil function during acute viral hepatitis
}

\author{
S. J. SAUNDERS, E. B. DOWDLE, C. FISKERSTRAND, M. BASSENDINE, AND \\ R. WALLS
}

From the MRC/UCT Liver Research Group, Department of Medicine and the Department of Clinical Science and Immunology, University of Cape Town, and Groote Schuur Hospital, Cape Town, South Africa

SUMMARY Sera from eight of 17 patients with acute viral hepatitis was deficient in its ability to support neutrophil bactericidal function in vitro. This defect appeared to be related to the viral infection itself. Sera from patients with drug hepatitis or mechanical obstructive jaundice did not show this effect.

Recent reports have indicated that patients with systematic disease may have transient disorders of polymorphonuclear leucocyte function (Quie, 1973). In the case of liver disease, impairment of polymorphonuclear leucocyte function has been reported in patients with massive liver cell necrosis (Bailey et al., 1976) and in children who are carriers of the hepatitis B surface antigen (HBsAG) (Vierucci et al., 1977). We have extended these observations by investigating the effect of sera from patients with acute viral hepatitis; with hepatitis caused by drug sensitivity, and with mechanical obstructive jaundice due to carcinoma or gallstones on the bactericidal activity of neutrophils obtained from control subjects. Since effective bacterial killing in vitro requires both intact cellular function and serum components, the experimental protocol was designed to test for defects in both of these factors.

\section{Methods}

SUBJECTS

Viral hepatitis

Seventeen patients with viral hepatitis were studied during the acute phase of the disease. In eight HBsAG was detectable in the plasma. All had raised serum bilirubin and serum glutamic oxalacetic transaminase levels at the time of the study. One patient died with acute hepatic encephalopathy and two others showed evidence of this complication.

Received for publication 27 April 1978
Of the 16 patients who recovered, none developed chronic hepatitis or became chronic HBsAG carriers, although in two patients it is too early to make this assessment.

\section{Drug-induced hepatitis}

Five patients had hepatitis caused by isonictotinic acid hydrazide and one by alpha methyl dopa.

\section{Mechanical obstructive jaundice}

Eleven patients had mechanical obstructive jaundice. In six this was due to carcinoma of the head of the pancreas; in four to carcinoma of the bile duct, and in one to a stone in the common bile duct.

\section{Control subjects}

Control subjects were healthy medical or laboratory personnel, or hospitalised patients without evidence of liver disease or other illness known to impair neutrophil function.

\section{TECHNIQUES}

\section{Determination of $H B s A G$}

The radioimmunoassay Austria II was used.

\section{Neutrophil bactericidal activity}

Neutrophils were isolated from heparinised venous blood by the method of Böyum (1967). Briefly, the blood was diluted with 3 volumes of $0.9 \% \mathrm{NaCl}$ and centrifuged $(200 \mathrm{~g} ; 45$ minutes; room temperature) on a layer of Ficoll-Hypaque (SG 1077). The plasma, the mononuclear cell layer, and the major fraction of the Ficoll-Hypaque were discarded. The 
erythrocyte/neutrophil pellet was resuspended in plasma and sedimented with dextran. Neutrophils were harvested from the plasma layer by centrifugation and brief exposure to $\mathrm{Tris} / \mathrm{NH}_{4} \mathrm{Cl}$ buffer to lyse contaminating erythrocytes. Cells isolated in this way comprised more than $98 \%$ neutrophils, more than $99 \%$ of which were viable as judged by trypan blue exclusion. Staphylococcus aureus of the Oxford strain was maintained on nutrient agar for use as the target organism. Before each test the bacteria were subcultured from an overnight tryptic soy broth culture to bring them to late $\log$ phase for use. The bacteria were finally suspended in RPMI and the concentration was measured turbidimetrically. The concentrations of the neutrophils and organisms were adjusted to give final concentrations in the assay tubes of $5 \times 10^{6} / \mathrm{ml}$ and $1 \times 10^{7} / \mathrm{ml}$ respectively. The incubation took place at $37^{\circ} \mathrm{C}$ with gentle mixing in the presence of $20 \%$ of the test serum for 120 minutes. The neutrophils of patients with viral hepatitis, drug hepatitis, and mechanical obstructive jaundice were assessed in this way in the presence of normal control AB serum, used throughout as a standard normal serum. Neutrophils from control subjects were tested in the presence of standard AB normal serum, and in the serum from patients with viral, druginduced, or mechanical obstructive jaundice. After incubation, the samples were sonicated in water to disrupt the cells without damaging the bacteria. The number of viable organisms was determined by colony count and the pour plate technique. For comparative purposes, bactericidal function was measured in terms of a 'killing index (KI)' calculated from viable counts after two hours of incubation as follows:

$\mathrm{KI}=100 \times$

$\left(1-\frac{\text { Viable count in the presence of neutrophils) }}{\text { Viable count in the absence of neutrophils }}\right)$

\section{Results}

INCUBATION OF NEUTROPHILS FROM CONTROL SUBJECTS WITH CONTROL

NORMAL AB SERUM

Forty-one subjects were studied. The mean killing index was 98.58 , with a standard deviation of 0.55 and a standard error of the mean of 0.09 . The mean killing index minus two standard deviations

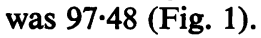

INCUBATION OF NEUTROPHILS FROM CONTROL SUBJECTS WITH HEPATITIS SERA Killing indices observed with control neutrophils incubated in the presence of serum from six patients

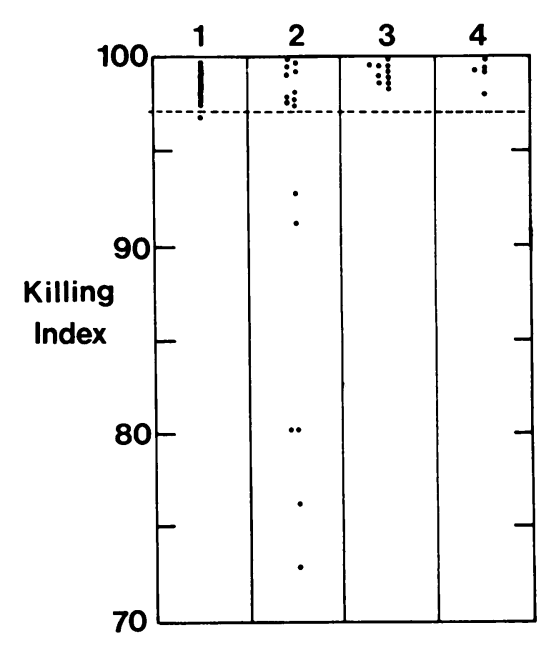

Fig. 1 The killing indices for normal neutrophils incubated in sera from patients with 1 (controls); 2 (viral hepatitis); 3 (mechanical obstructive jaundice), and 4 (drug hepatitis), are shown. The dotted line represents the lower limit of 2 standard deviations of the mean.

with viral hepatitis were less than 97.48 and were, therefore, regarded as being significantly reduced below the control figure $(P<0.0005)$. In contrast, a further 10 patients with viral hepatitis (indicated in Table 1 as having 'normal' killing indices) had killing indices which fell within the defined normal range. Sera from five patients with drug hepatitis and 10 patients with mechanical obstructive jaundice all showed normal killing indices (Table 2). At a clinical level there were no features to distinguish those patients with viral hepatitis whose serum showed significantly low killing indices from those in whom serum supported normal killing indices. Two of the patients with sera causing a low killing index were encephalopathic, one being in grade II hepatic encephalopathy, and one dying after being in grade IV encephalopathy. One of the patients with a normal killing index was in grade II hepatic encephalopathy when tested. Two of the patients showing the serum abnormality were HBsAG positive; one of these became negative after nine weeks, and the other remains positive but his illness has lasted only two weeks at this stage. Of those whose serum supported normal neutrophil activity, six were HBsAG positive initially and four became negative. There were no significant differences between the two groups with regard to the total white cell count, the differential leucocyte count, the platelet count, the serum urea, uric acid, alkaline phosphatase, AAT, total 
Table 1 Viral hepatitis

\begin{tabular}{|c|c|c|c|c|c|c|c|c|}
\hline & & $\begin{array}{l}\text { Age } \\
\text { (yr) }\end{array}$ & $\operatorname{Sex}$ & $\begin{array}{l}\text { Total bilirubin } \\
(\mu \mathrm{mol} / l)\end{array}$ & $I U A A T$ & $H B s A G$ & $\boldsymbol{K I}$ & Comment \\
\hline \multicolumn{9}{|c|}{ Low killing index } \\
\hline 1 & $\begin{array}{l}\text { DG } \\
\mathbf{A B}\end{array}$ & $\begin{array}{l}32 \\
35\end{array}$ & $\begin{array}{l}\mathbf{F} \\
\mathbf{M}\end{array}$ & $\begin{array}{l}348 \cdot 7 \\
170 \cdot 9\end{array}$ & $\begin{array}{l}>300 \\
>300\end{array}$ & $\overline{+}$ & $\begin{array}{l}91 \cdot 4 \\
93 \cdot 2\end{array}$ & $\begin{array}{l}\text { Grade II hepatic encephalopathy. } \\
\text { Became HBsAG negative after } \\
2 \mathrm{w}\end{array}$ \\
\hline 3 & $\mathbf{A B}$ & 32 & $\mathbf{M}$ & $317 \cdot 9$ & 114 & - & $80 \cdot 1$ & \\
\hline 4 & PE & 59 & $\mathbf{M}$ & $328 \cdot 2$ & $>300$ & - & $76 \cdot 4$ & $\begin{array}{l}\text { Grade IV hepatic } \\
\text { encephalopathy. Died. }\end{array}$ \\
\hline 5 & JK & 55 & $\mathbf{M}$ & $46 \cdot 2$ & 207 & - & $73 \cdot 5$ & $\begin{array}{l}\text { Rising titre Paul Bunnell; } \\
\text { infectious mononucleosis }\end{array}$ \\
\hline 6 & $\mathbf{B M}$ & 33 & $\mathbf{M}$ & $102 \cdot 6$ & 25 & + & $80 \cdot 1$ & \\
\hline \multicolumn{9}{|c|}{ Normal killing index } \\
\hline 7 & MD & 37 & $\mathbf{F}$ & $95 \cdot 7$ & $>300$ & - & $97 \cdot 9$ & $\begin{array}{l}\text { Grade II hepatic } \\
\text { encephalopathy }\end{array}$ \\
\hline $\begin{array}{l}8 \\
9\end{array}$ & $\begin{array}{l}\text { FP } \\
\text { MD }\end{array}$ & $\begin{array}{l}32 \\
30\end{array}$ & $\begin{array}{l}\mathbf{F} \\
\mathbf{F}\end{array}$ & $\begin{array}{r}160.7 \\
46.2\end{array}$ & $\begin{array}{l}85 \\
71\end{array}$ & - & $\begin{array}{l}98 \cdot 7 \\
99 \cdot 7\end{array}$ & \\
\hline 10 & EB & 28 & $\mathbf{M}$ & $140 \cdot 2$ & $>300$ & + & $98 \cdot 1$ & HBsAG negative after $4 \mathrm{w}$ \\
\hline 11 & JB & 30 & $\mathbf{F}$ & $85 \cdot 5$ & $>300$ & - & $99 \cdot 8$ & \\
\hline 12 & AK & 55 & $\mathbf{M}$ & $482 \cdot 1$ & $>300$ & + & 98.9 & HBsAG negative after $7 \mathrm{w}$ \\
\hline 13 & JduT & 40 & $\mathbf{M}$ & $56 \cdot 4$ & $>\mathbf{3 0 0}$ & + & $99 \cdot 3$ & HBsAG negative after $6 \mathrm{w}$ \\
\hline 14 & $\mathbf{A Q}$ & 32 & $\mathbf{M}$ & $112 \cdot 8$ & 160 & + & $98 \cdot 4$ & HBsAG negative after $6 \mathrm{w}$ \\
\hline 15 & GV & 28 & $\mathbf{M}$ & $162 \cdot 4$ & 138 & + & $98 \cdot 2$ & Still HBsAG positive after $1 \mathrm{~m}$ \\
\hline 16 & CB & 70 & $\mathbf{F}$ & $153 \cdot 8$ & 232 & + & $99 \cdot 1$ & Still HBsAG positive after $2 \mathrm{w}$ \\
\hline
\end{tabular}

Table 2 Drug hepatitis and mechanical obstructive jaundice

\begin{tabular}{|c|c|c|c|c|c|c|c|c|}
\hline & & $\begin{array}{l}\text { Age } \\
(y r)\end{array}$ & Sex & $\begin{array}{l}\text { Total bilirubin } \\
(\mu \mathrm{mol} / l)\end{array}$ & $A A T I U$ & $H B s A G$ & $\boldsymbol{K} \boldsymbol{I}$ & Comment \\
\hline \multicolumn{9}{|c|}{ Drug hepatitis } \\
\hline 1 & CM & 18 & $\mathbf{F}$ & $158 \cdot 9$ & 66 & - & $99 \cdot 4$ & INH \\
\hline 2 & $\mathbf{K L}$ & 28 & $\mathbf{F}$ & $141 \cdot 9$ & $>300$ & - & $99 \cdot 2$ & Grade II encephalopathy. INH \\
\hline$\overline{3}$ & LeKY & 18 & $\mathbf{M}$ & $12 \cdot 0$ & 94 & - & $99 \cdot \overline{7}$ & INH \\
\hline 4 & WS & 26 & $\mathbf{M}$ & $44 \cdot 4$ & 105 & - & $99 \cdot 3$ & INH \\
\hline 5 & HG & 74 & $\mathbf{F}$ & $239 \cdot 3$ & $>300$ & - & $98 \cdot 6$ & Methyldopa \\
\hline \multicolumn{9}{|c|}{ Mechanical obstructive jaundice } \\
\hline 1 & SduP & 60 & $\mathbf{F}$ & $432 \cdot 3$ & $>300$ & - & $99 \cdot 5$ & Carcinoma of pancreas \\
\hline 2 & MH & 90 & $\mathbf{F}$ & $292 \cdot 3$ & 150 & - & $99 \cdot 8$ & Carcinoma of pancreas \\
\hline 3 & NH & 71 & $\mathbf{F}$ & $198 \cdot 3$ & 164 & - & $98 \cdot 1$ & Carcinoma of pancreas \\
\hline 4 & DC & 76 & $\mathbf{M}$ & $261 \cdot 5$ & 156 & - & $98 \cdot 2$ & Carcinoma of pancreas \\
\hline 5 & $\overline{E N}$ & 58 & $\mathbf{M}$ & $201 \cdot 7$ & 253 & - & $98 \cdot 3$ & Carcinoma of common bile duct \\
\hline 6 & VS & 40 & $\mathbf{M}$ & $157 \cdot 3$ & 100 & - & $99 \cdot 5$ & Carcinoma of common bile duct \\
\hline 7 & RS & 60 & $\mathbf{F}$ & $147 \cdot 0$ & 150 & - & $99 \cdot 5$ & Stone in common bile duct \\
\hline 8 & MB & 62 & $\mathbf{F}$ & $170 \cdot 9$ & 92 & - & $98 \cdot 9$ & Carcinoma of pancreas \\
\hline 10 & CS & 28 & $\mathbf{M}$ & $75 \cdot 2$ & 143 & - & $99 \cdot 3$ & Carcinoma of common bile duct \\
\hline
\end{tabular}

protein, albumin, alpha 1 , alpha 2 , beta or gammaglobulin, IGG, IGM, total complement, or the third component of complement. The serum IGA was significantly higher (mean of 286) in those with lower killing indices than in the other group (mean 202, P < 0.025). The total bilirubin was significantly higher in those patients whose serum gave diminished killing indices (mean $17 \cdot 1$ ) than in those whose serum did not (mean 8.9). However, there were no differences between the height of the serum bilirubin in the hepatitis patients whose sera were associated with a lowered killing index, and those patients with mechanical obstructive jaundice (mean 16.1) whose sera did not show any effect on the killing index. Indeed, the patients with mechanical obstructive jaundice and drug hepatitis showed no significant variation in any of the measurements described from this group of patients with infective hepatitis. This also holds true for their total plasma IGA levels (mean in mechanical obstructive jaundice 268 , and in drug hepatitis 350 ).

Figure 2 shows the results of the killing indices measured with normal neutrophils in the presence of sera from two patients with viral hepatitis at the onset of the disease and after the hepatitis had resolved completely. It can be seen that in both instances the initial lowering of the killing index had disappeared when it was tested a second time after the illness had resolved. By this time the one 




Fig. 2 The killing indices of normal neutrophils incubated with sera from two patients with viral hepatitis at the onset of the disease (initial) and after recovery ( final). The shaded area represents 2 standard deviations of the mean.

patient, who had been HBsAG positive, was HBsAG negative. Appropriate control experiments have shown that storing the serum at $-80^{\circ} \mathrm{C}$ had no significant effect upon the ability of serum to support neutrophil bactericidal function.

\section{INCUBATION OF NEUTROPHILS OF}

PATIENTS WITH CONTROL AB SERUM

In each of the groups with viral hepatitis, mechanical obstructive jaundice, and drug hepatitis, there were two patients whose neutrophils gave killing indices less than 97.48 when incubated with normal AB control serum. There was no correlation with any abnormal biochemical or other findings in these patients. In the infective hepatitis group patient no. 4 (P.E.) had a killing index of 96.9 , and patient no. 16 (C.B.) one of 94 (Table 1). In the group with obstructive jaundice patient no. 5 (E.N.) had a killing index of 95.8 , and patient no. 1 (S. duP.) one of $95 \cdot 6$, while in the drug hepatitis group patient no. 1 (C.M.) had a killing index of 95.5, and patient no. 2 (K.L.) one of 95.4 (Table 2). These abnormalities were not investigated further.

\section{Discussion}

Bactericidal function of normal neutrophils was significantly depressed when they were incubated with the serum of six of 16 patients with viral hepatitis, while the serum of five patients with drug-induced hepatitis and 11 patients with mechanical obstructive jaundice did not show this effect. This serum abnormality could not be related to the presence of HBsAG nor did it correlate with any other clinical, biochemical, or immunological abnormality. In particular, only two of the six sera which were associated with a lowered killing index had concentrations of total complement and C3 below normal. The other four were well within the normal range. The capacity of the serum to support neutrophil bactericidal function improved with the clinical and biochemical recovery in the two patients in whom this was studied.

Vierucci et al. (1977) demonstrated that the bactericidal activity of neutrophils was significantly reduced in children who were chronic carriers of the HBsAG, and they also demonstrated that these patients showed a higher proportion of stimulated neutrophils when studied with the histochemical nitroblue tetrazolium (NBT) test. HBsAG particles were not detected in the neutrophils and they postulated that, if the defects in neutrophil function in the HBsAG carrier children preceded their hepatitis B infections, these could have influenced the development of the carrier state. In keeping with the experience of others, they found conflicting data when they used the quantitative NBT test. Bailey et al. (1976) were unable to demonstrate any intrinsic leucocyte abnormality in patients with fulminant hepatic failure, but showed that there was a factor in the serum of these patients which was able to inhibit the metabolic activity of the leucocyte hexose monophosphate shunt as measured by the conversion of $\mathrm{C}\left(1-{ }^{14} \mathrm{C}\right)$-glucose to ${ }^{14} \mathrm{CO}_{2}$. This correlated with neither the low serum complement nor the associated renal failure. They noted that the inhibitory factor was dialysable and could be removed by treatment of the serum with activated charcoal. They postulated that various forms of artificial support might improve polymorphonuclear function in these patients who have a high incidence of bacterial infection. Of the 28 patients whom they studied, the liver damage was caused by paracetamol overdose in 13 , while 12 had viral hepatitis, in two of whom it was thought to be type B. Three of the patients had halothaneassociated hepatitis. Two of our patients had encephalopathy, one of whom died of liver failure, but one of the patients, whose serum did not show this effect, was also in grade II hepatic encephalopathy. In our patients the serum factor was not related to the severity of the disease, and, unlike the patient of Bailey et al. (1976), was confined to patients who had viral hepatitis. 
Larson and Blades (1976) examined the effects of an influenza virus on polymorphonuclear leucocyte function in vitro and demonstrated that the ability of human neutrophils to show chemotaxis and to phagocytose the staphylococcus was inhibited when they were incubated with influenza viruses. In this experimental model hexose monophosphate shunt activity was unaffected, and they concluded that the inhibitory effects were specific to the virus. They related these alterations in the leucocyte to the high incidence of bacterial pneumonia accompanying influenza in man. The intrinsic defect in neutrophil function shown in some patients with viral hepatitis, drug hepatitis, and mechanical obstructive jaundice has not been investigated further, and the cause is obscure.

We conclude that it is likely that the hepatitis virus, or a product of the virus, is responsible for a serum abnormality which manifests as an inability to support normal neutrophil function in some patients with viral hepatitis.

\section{References}

Bailey, R. J., Woolf, I. L., Cullens, H., and Williams, R. (1976). Metabolic inhibition of polymorphonuclear leucocytes in fulminant hepatiz failure. Lancet, 1,1162-1163. Böyum, A. (1967). Isolation of leucocytes from human blood. Further observations. Scandinavian Journal of Clinical and Laboratory Investigation, 21, suppl. 97, 31-50.

Larson, H. E., and Blades, R. (1976). Impairment of human polymorphonuclear leucocyte function by influenza virus. Lancet, 1, 283.

Quie, P. G. (1973). Polymorphonuclear leukocyte dysfunction in patients with severe infections. In Non-specific Factors Influencing Host Resistance. A Reexamination, pp. 68-72. Edited by W. Braun and J. Ungar. Karger: Basel.

Vierucci, A., de Martino, M., London, W. T., and Blumberg, B. S. (1977). Neutrophil function in children who are carriers of hepatitis-B surface antigen. Lancet, 1, 157-160. 